\title{
Successful and unsuccessful approaches to imaging carcinoids: comparison of a radiolabelled tryptophan hydroxylase inhibitor with a tracer of biogenic amine uptake and storage, and a somatostatin analogue
}

\author{
D. Macfarlane1, J. Gonin², D. Wielandl, T. Mangner ${ }^{3}$, J. Froelich ${ }^{4}$, W. Beierwaltes ${ }^{5}$, B. Shapirol \\ 1 Department of Nuclear Medicine, Royal Brisbane Hospital, Queensland, Australia \\ 2 Department of Nephrology, Indianapolis VA Hospital, Indianapolis, Indiana, USA \\ ${ }^{3}$ Department of Nuclear Medicine, Children's Hospital of Detroit, Detroit, Michigan, USA \\ ${ }^{4}$ Department of Radiology, Swedish Medical Center, Englewood, Colorado, USA \\ 5 Department of Nuclear Medicine, St. John's Hospital, Detroit, Michigan, USA
}

Received 16 May and in revised form 4 September 1995

\begin{abstract}
A mouse mastocytoma model was used to determine the biodistribution and tumour uptake of four radiopharmaceuticals developed to target the serotonin synthetic pathway in carcinoid tumours. Three of the compounds were competitive inhibitors of the rate-limiting enzyme of serotonin synthesis, tryptophan hydroxylase. Radiolabelled iodo-DL-phenylalanine (iodine-131 PIPA) was found to have the highest uptake and tumourto-liver ratio. Four patients with known carcinoid tumours were then injected with $0.5 \mathrm{mCi}{ }^{131}$ I-PIPA and imaged at 1, 4, 24 and $48 \mathrm{~h}$ post-injection. The radiopharmaceutical, however, failed to localize in the known tumour sites. This result was in contrast to the authors' experience of ${ }^{131} \mathrm{I}$ - and ${ }^{123} \mathrm{I}-\mathrm{MIBG}$ imaging of carcinoid tumours. Seven patients with known metastatic carcinoid tumours, two patients with symptoms of recurrence following tumour resection, one patient with completely resected disease, and two patients with a flushing syndrome of uncertain aetiology were studied with 131IMIBG. Three of the seven patients with known metastatic disease had positive ${ }^{131} \mathrm{I}-\mathrm{MIBG}$ scans. Both patients with clinical evidence of recurrent disease had negative scans, as did the patient who was considered to have had complete resection of her primary tumour. The two patients with idiopathic flushing syndrome also had negative scans. Among seven patients imaged with 123IMIBG there were four true-negative scans and one falsenegative, the latter in a patient with biochemical and CT evidence of recurrence. In a seventh patient with distant metastases there was variable uptake in some of the lesions. Four patients were studied with indium-111 penetetreodide. Two patients with metastatic carcinoid dis-
\end{abstract}

Correspondence to: Dr. B. Shapiro, Division of Nuclear Medicine, University of Michigan Medical Center, B1G412, 1500 East Medical Center Drive, Ann Arbor, Michigan, 48109-0028. USA ease had positive scans, although hepatic metastases were not seen in one. Another two with idiopathic flushing syndrome had normal studies. The literature suggests that up 50\% of carcinoid tumour cases are detected with ${ }^{131}$ I-MIBG, compared to a sensitivity of $87 \%$ reported with somatostatin receptor imaging using ${ }^{111}$ In-pentetreotide. The experience with ${ }^{123}$ I-MIBG is much less extensive. The mechanisms of carcinoid tumour localization for each of the three classes of radiotracers are discussed and contrasted to their varying sensitivities. The relative success of ${ }^{131} \mathrm{I}-\mathrm{MIBG}$ and ${ }^{111} \mathrm{In}$-pentetreotide relative to ${ }^{131}$ I-PIPA may be related to the fact that ${ }^{131}$ I-MIBG is actively taken up and stored by the enterochromaffin cells of the tumours and ${ }^{111}$ In-pentetreotide binds to cell surface receptors, whereas ${ }^{131}$ I-PIPA binds to tryptophan hydroxylase, which may be present in quantities too small to permit tumours to be imaged.

Key words: Carcinoid - Radionuclide imaging - Phenylalanine - Metaiodobenzylguanidine - Pentetreotide Iodophenylalanine

Eur J Nucl Med (1996) 23:131-140

\section{Introduction}

Carcinoid tumours are derived from the enterochromaffin cells of the gastrointestinal tract. They are considered to be neuroectodermal derivatives forming part of the APUD series of tumours. These tumours may produce a number of vasoactive amines and peptides which play a role in the development of the carcinoid syndrome. These substances include serotonin (5-hydroxytryptamine), prostaglandins, substance $P$, kallikrein, histamine, 


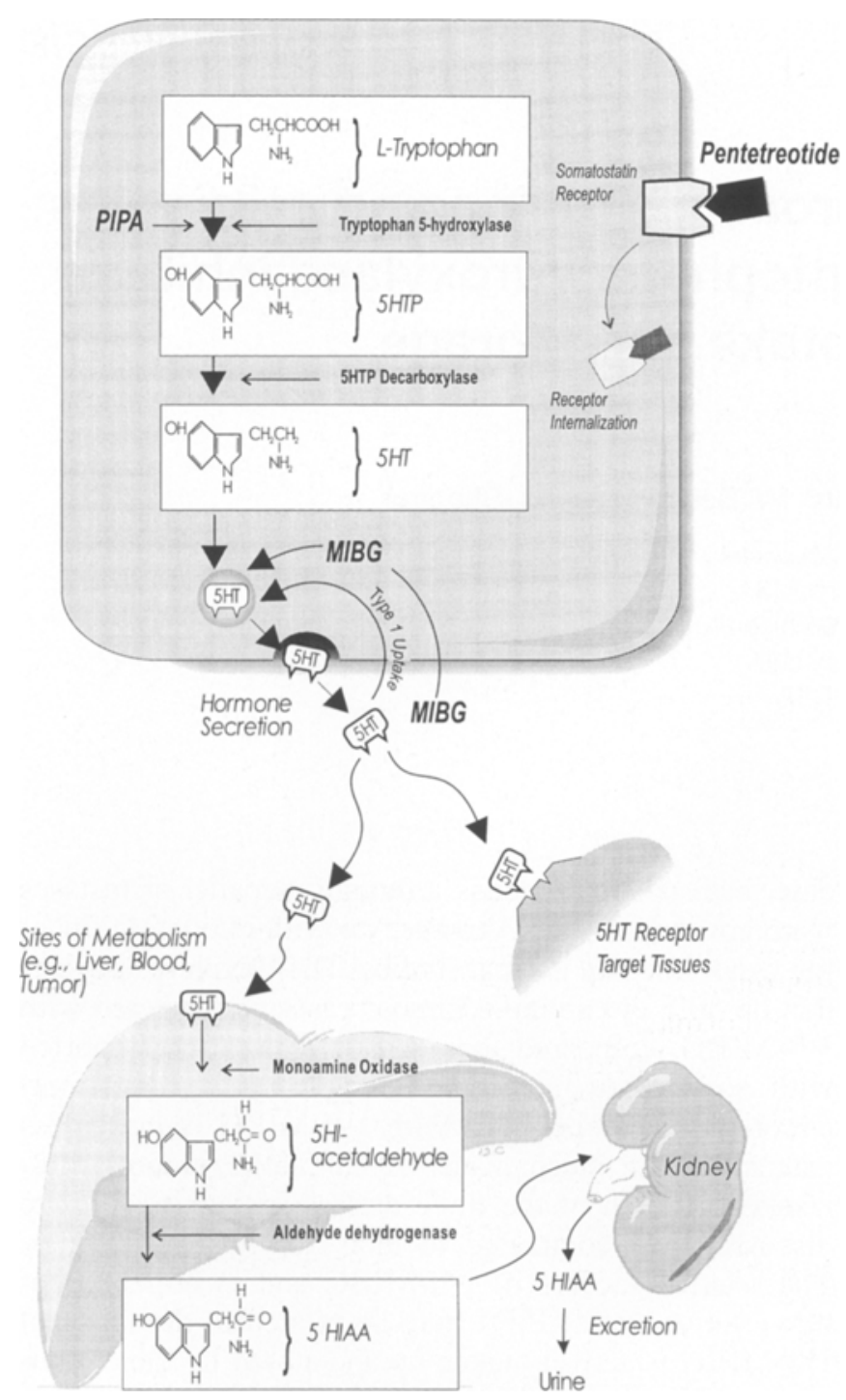

Fig. 1. Diagrammatic illustration of serotonin metabolism, highlighting points of action of various scintigraphic agents for carcinoid imaging (5HTP 5-hydroxytryptophan, 5HT 5-hydroxytryptamine (serotonin), 5HIAA 5-hydroxyindoleacetic acid, PIPA $p$ iodophenylalanine, $M I B G$ meta-iodobenzylguanidine). Note that there are believed to be at least five subtypes of somatostatin receptors

dopamine and neuropeptide $\mathrm{K}[1,2]$. As serotonin is synthesized in large quantities within these tumours, this unique synthetic pathway is an obvious target for compounds designed to selectively localize in carcinoids.

The serotonin biosynthetic pathway involves two enzymatic steps (Fig. 1). Tryptophan 5-hydroxylase catalyses the hydroxylation of tryptophan to 5-hydroxytryptophan (5-HTP) and 5-HTP decarboxylase (dopa decarboxylase) catalyses the decarboxylation of 5-HTP to 5hydroxytryptamine. Competitive inhibitors of the ratelimiting enzyme, tryptophan-5-hydroxylase, have been shown to at least partially alleviate the carcinoid syndrome in a number of cases $[3,4]$. For this reason, radiolabelled inhibitors of this enzyme have been considered as potential agents for the imaging of carcinoid tumours.
Costella used iodine-131 5-iodotryptophan in two patients with known metastatic carcinoid disease, with liver metastases being visualized in one [5].

Serotonin is stored in cytoplasmic membrane-bounded vesicles following synthesis (see Fig. 1). The vesicular contents are discharged following depolarization of the cell membrane by rapid sodium and slow calcium currents which cause fusion of the vesicular membrane with the cell membrane and exocytosis of the vesicle contents. Many cells of the APUD series, including carcinoids, have a type 1 biogenic amine active reuptake mechanism by which extracellular amines are concentrated across the cell membrane into the cytoplasm. The radiopharmaceutical metaiodobenzylguanidine (MIBG) exploits this mechanism to image a wide range of neuroendocrine tumours. The largest experience has been with phaeochromocytomas and neuroblastomas, although carcinoids have also been successfully imaged [6].

The inhibition of carcinoid secretory activity by somatostatin and its analogues is a well-established phenomenon [7]. Autoradiography of tissue specimens from carcinoid tumours has demonstrated expression of somatostatin tissue receptors (SSTRs) in approximately $87 \%$ of cases [8]. These receptors are widely distributed in tissues of neuroendocrine origin as well as in brain, kidney and lymphocytes. In some cell lines receptor expression is inversely related to tumour differentiation [9]. Long-acting somatostatin analogues labelled with iodine-123 and more recently indium-111 have proven to be practical agents for the in vivo visualization of carcinoid and many other somatostatin receptor-positive tumours [6].

The main purpose of this study was to investigate the use of radiolabelled tryptophan hydroxylase inhibitors as potential radiopharmaceuticals for the imaging of carcinoid tumours. The study design comprised two phases. Firstly, a number of tryptophan hydroxylase inhibitors were synthesized, radiolabelled and administered to animals bearing a serotonin-synthesizing tumour in order to determine the tissue distribution and toxicity of these compounds. Following this, using the compound with the best target-to-background ratio in the animal model, an attempt was made to image known carcinoid tumours in four patients. We also compare and contrast this approach with our experience and those of others using ${ }^{131} \mathrm{I}$ - and ${ }^{123} \mathrm{I}-\mathrm{MIBG}$ and ${ }^{111}$ In pentetreotide to image carcinoid tumours.

\section{Study design and results}

\section{Materials and methods: phase 1}

Radiolabelled serotonergic agents of two general classes were prepared and tested. Three radiolabelled tryptophan hydroxylase inhibitors were synthesized: 5-iodotryptophan (125I-5-ITP), 6-iodotryptophan (125I-6-ITP), ${ }^{131}$ I- $p$-iodo-DL-phenylalanine (131 I-PIPA) and ${ }^{125 I-p-}$ 
iodo-DL-phenylalanine (125I-PIPA). Meta-4-iodoamphetamine (125I-PIA), a compound directly toxic to tryptophan hydroxylase-secreting cells of the brain, was also synthesized.

The ${ }^{125}$ I-iodotryptophans were produced by exchange-labelling the corresponding ${ }^{127} \mathrm{I}$ compounds under aqueous conditions. Radiochemical yields of up to $70 \%$ and specific activities (determined by ultraviolet spectroscopy) of 0.3 and $0.5 \mathrm{mCi} / \mu \mathrm{mol}$ were obtained [10]. The ${ }^{127} \mathrm{I}$ iodotryptophans were synthesized by Mangner et al. from their respective nitroindoles by a seven-step sequence modified from the procedure of Lambrecht et al. for overall yields of 20\%-25\% [11]. The "cold" iodoamphetamine was prepared by a threestep sequence from 4-iodobenzaldehyde and then radiolabelled by exchange in a melt [10].

For tissue distribution studies, a mouse mastocytoma model (LAF-1 mastocytoma, Mason Research Institute, Worcester, Mass.) was chosen. The mouse mastocytoma is a solid, rapidly growing tumour which, like the carcinoid tumour, produces substantial quantities of serotonin $[12,13]$. In addition, the biochemical properties of tryptophan hydroxylase isolated from this type of neoplasm have been reported to be very similar to those isolated from carcinoid tumours $[14,15]$. Unlike the preliminary studies for the development of adrenal sympathomedullary tumour imaging agents, in which the normal adrenal medulla served as an experimental target organ, the development of an agent for the imaging for carcinoid tumours has been hampered by the fact that enterochromaffin cells are not concentrated into a focal organ but rather form a diffuse system distributed throughout the body. It was therefore necessary to use the animal tumour model described above for tissue distribution studies.

The tumours were implanted in $15 \mathrm{LAF}-1$ mice $(25 \mathrm{~g})$ and grown for 13 days. Three LAF-1 mice per compound per time interval were injected with each of the ${ }^{125} \mathrm{I}$ compounds and tissue distribution of these compounds was determined at $1.5 \mathrm{~h}$ and $4 \mathrm{~h}$ post intraperitoneal injection of $26 \mu \mathrm{Ci}$ of the radiopharmaceutical. The specific activities of the radiopharmaceuticals tested were: 5-iodotryptophan: $0.67 \mathrm{mCi} / \mathrm{mg} ;$ 6-iodotryptophan: $0.16 \mathrm{mCi} / \mathrm{mg}$; 4-iodophenylalanine: $0.44 \mathrm{mCi} / \mathrm{mg}$; and 4-iodoamphetamine: $0.85 \mathrm{mCi} / \mathrm{mg}$.

\section{Results: phase I}

Uptake of the radiopharmaceutical compounds was measured in the tumour, liver, thyroid, pancreas, intestine, muscle and blood (Table 1). From these data it can be seen that although each of these compounds localized selectively in the mastocytoma, the best uptake $(0.23 \%$ $\mathrm{kg} \mathrm{dose} / \mathrm{g}$ ) and tumour-to-liver ratios (5.5) were obtained with ${ }^{125}$ I-PIPA. On the basis of these results radioiodinated PIPA was selected for further study as a tumour imaging agent in an extension of the in vitro work. As

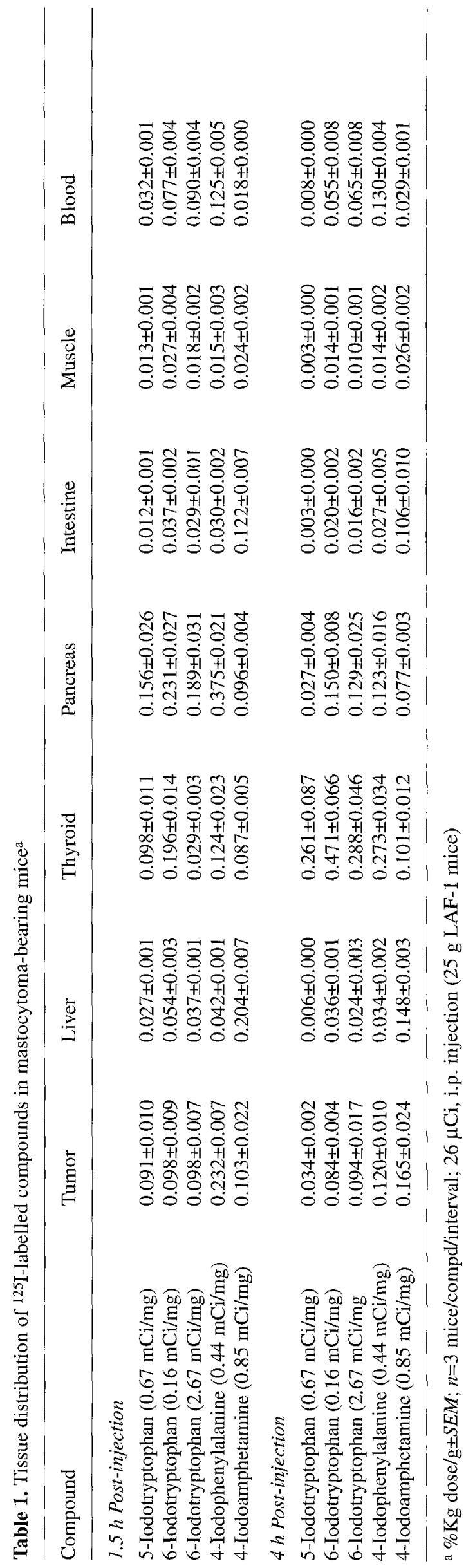


125I-labelled compounds are unsuited to in vivo scintigraphy it was decided to use ${ }^{131}$ I-PIPA in the human studies.

\section{Materials and methods: phase II}

${ }^{131}$ I-PIPA was prepared using the method detail above. Thin-layer chromatography of the product was performed. A sample of the product was dissolved in an acetate buffer with $1 \%$ benzyl alcohol, and thin-layer chromatography performed using thin-layer silica gel (K6F) with both EtOH:EtOAc: $\mathrm{NH}_{4} \mathrm{OH}(20: 20: 1)$ and $\mathrm{BuOH}: \mathrm{AcOH}: \mathrm{H}_{2} \mathrm{O}(5: 2: 1)$ solvent systems. No free ${ }^{131} \mathrm{I}$ as iodide was detected.

Acute toxicity studies were carried out by administering $5 \mathrm{mg} / \mathrm{kg}$ PIPA to five rats and two $\mathrm{mg} / \mathrm{kg}$ PIPA to three dogs. A matched control group was selected for each species. No drugs were administered to the control groups. No adverse reactions or deaths were observed in any group over a 5-day observation period. The animals were then sacrificed and samples of ovary, liver, small and large intestine, spleen, lung and pancreas from subjects in experimental and control groups were submitted for histological examination. No specific drug-related histopathological alterations were seen in specimens from control or experimental animals of either species.

Although no toxicity data were available in humans for 131I-PIPA, reports documenting the use of the chlorinated analogue, parachlorophenylalanine, in the treatment of carcinoid syndrome describe dose-related sideeffects only at doses greater than $2 \mathrm{~g}[3,16]$.

MIRD formalism was used in the calculation of the radiation dosimetry of ${ }^{131}$ I-PIPA using biodistribution data derived from rats and the assumption that the dosimetry in humans would parallel that in the rats [16]. Organ activity-concentration in rats administered 100 $\mu \mathrm{Ci}{ }^{131}$ I-PIPA was calculated using an ionization chamber. Table 2 summarizes the results for the dosimetric calculations.

Four patients with known metastatic carcinoid tumours were studied. All four patients had extensive metastatic involvement of the liver. Three of the patients had primary small bowel tumours and in one patient the site of the primary tumour was unknown (Table 3).

The patients were injected with $0.50-0.53 \mathrm{mCi}{ }^{131} \mathrm{I}-$ PIPA, corresponding to approximately $0.1 \mathrm{mg}$ of PIPA or $1.4-5.7 \mathrm{mg} / \mathrm{kg}$, a dose well within the reported safety limits for $p$-chlorophenylalanine and representing a safety margin exceeding 350:1 based on our acute toxicity studies [3, 5]. All patients received one drop of saturated solution of potassium iodide ( $38 \mathrm{mg}$ iodide) 3 times daily starting $24 \mathrm{~h}$ prior to and continuing for $48 \mathrm{~h}$ after tracer administration to achieve thyroid blockade. Urine, faeces and blood were sampled at intervals over a $48-\mathrm{h}$ period. Subjects were scanned at $0-1 \mathrm{~h}, 4 \mathrm{~h}, 24 \mathrm{~h}$ and $48 \mathrm{~h}$ post-injection using a wide-field-of-view gamma camera (Pho Gamma) fitted with a high-energy, parallel-
Table 2. Estimated internal radiation dose $/ 0.5 \mathrm{mCi}^{131}{ }^{1}-\mathrm{PIPA}^{\mathrm{a}}$

\begin{tabular}{ll}
\hline Organ & $\mathrm{cGy} / 0.5 \mathrm{mCi}$ \\
\hline Adrenal & 0.82 \\
Liver & 0.67 \\
Ovaries & 0.60 \\
Kidneys & 0.63 \\
Spleen & 0.61 \\
Pancreas & 0.97 \\
Heart & 1.01 \\
Lung & 0.59 \\
Small intestine wall & 0.51 \\
Large intestine wall & 0.53 \\
Thyroid (unblocked) & 33.7 \\
Thyroid (blocked) & 3.37 \\
Total body & 0.32 \\
\hline
\end{tabular}

a Based on biodistribution in rats and using MIRD formalism

hole collimator. Overlapping planar images of $20 \mathrm{~min}$ duration were acquired of the trunk in a $64 \times 64$ matrix.

\section{Results: phase II}

Excretion and blood activity data for ${ }^{131}$ I-PIPA are summarized in Table 3 , which demonstrates that the majority of activity is excreted via the urine and very little in the faeces. In all four patients studied the 131I-PIPA failed to localize at sites of known tumour involvement. The human scintigraphic biodistribution of ${ }^{131}$ I-PIPA is depicted in Fig. 2.

\section{Materials and methods: ${ }^{131} I$ and I23I-MIBG studies}

Since 1984, we have performed ${ }^{131}$ I-MIBG scintigraphy on 12 patients with confirmed or suspected carcinoid tumour, and six other patients were studied with ${ }^{123} \mathrm{I}$ MIBG. Our experience with ten of these patients was reported previously [17]. The salient clinical features are summarized inTable 4 . Of the 18 patients, six had histologically proven metastatic disease and one an unresected primary lesion, two patients had clinical symptoms highly suggestive of metastatic spread following resection of the primary tumour, and one patient had had the primary tumour completely excised with no evidence of local or distant disease at the time of imaging. The remaining five patients had an idiopathic flushing syndrome without radiological or conclusive biochemical evidence of carcinoid tumour. A prolonged interval between the trials with ${ }^{131}$ I-PIPA and ${ }^{131}$ I- and 123 I-MIBG precluded the same patients being studied with both agents. Six patients were studied with ${ }^{123}$ I-MIBG: three with idiopathic flushing syndrome, one with a resected single primary, and one patient each with local and distant metastases (Table 4).

Each patient was administered $0.5 \mathrm{mCi}{ }^{131} \mathrm{I}-\mathrm{MIBG}$ (specific activity $2.9-3.6 \mathrm{mCi} / \mathrm{mg}$ ) intravenously and im- 
Table 3. Clinical data, serum clearance and excretion data in patients following injection with ${ }^{131}$ I-PIPA

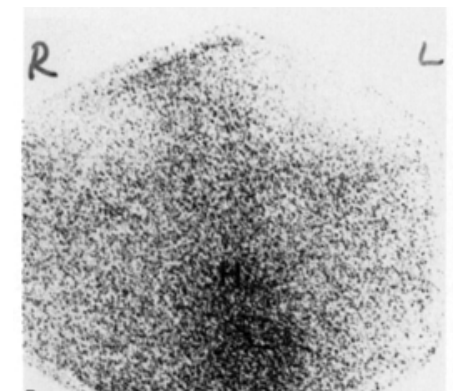

A

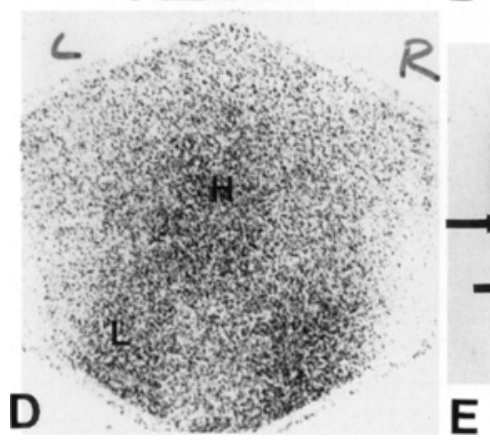

\begin{tabular}{|c|c|c|c|c|}
\hline Patient & 1 & 2 & 3 & 4 \\
\hline Age (years) & 54 & 58 & 35 & 64 \\
\hline $\begin{array}{l}\text { Primary } \\
\text { tumour }\end{array}$ & Small bowel & Ileum & Jejunum & Unknown \\
\hline Metastases & Liver & $\begin{array}{l}\text { Liver } \\
\text { spine } \\
\text { kidney }\end{array}$ & Liver & $\begin{array}{l}\text { Liver } \\
\text { adrenals }\end{array}$ \\
\hline \multicolumn{5}{|l|}{ Urine $0-3 \mathrm{~h}$} \\
\hline$\%$ Dose/g & 0.0384 & 0.0345 & 0.0275 & 0.0529 \\
\hline$\%$ Dose & 16.68 & - & - & 5.13 \\
\hline \multicolumn{5}{|l|}{ Urine $6-12 \mathrm{~h}$} \\
\hline \% Dose/g & 0.0107 & 0.0132 & 0.0173 & 0.0381 \\
\hline$\%$ Dose & 7.52 & - & & 4.95 \\
\hline \multicolumn{5}{|l|}{ Urine $24-48 \mathrm{~h}$} \\
\hline \% Dose/g & 0.0041 & 0.0056 & 0.0061 & 0.0058 \\
\hline$\%$ Dose & 5.79 & - & - & 12.51 \\
\hline \multicolumn{5}{|l|}{ Faeces 0-24 h } \\
\hline \% Dose/g & 0.0005 & 0.0022 & 0.0001 & 0.0010 \\
\hline$\%$ Dose & 0.091 & - & - & 0.099 \\
\hline \multicolumn{5}{|c|}{ Faeces $24-48 \mathrm{~h}$} \\
\hline \% Dose/g & 0.0006 & 0.0012 & 0.0004 & 0.0004 \\
\hline$\%$ Dose & 0.105 & - & - & 0.078 \\
\hline \multicolumn{5}{|l|}{ Serum $1 \mathrm{~h}$} \\
\hline \% Dose/g & 0.0040 & 0.0036 & 0.0046 & - \\
\hline \multicolumn{5}{|l|}{ Serum $4 \mathrm{~h}$} \\
\hline$\%$ Dose/g & 0.0042 & 0.0036 & 0.0045 & 0.0045 \\
\hline \multicolumn{5}{|l|}{ Serum $24 \mathrm{~h}$} \\
\hline \% Dose/g & 0.0022 & 0.0027 & 0.0034 & 0.0033 \\
\hline \multicolumn{5}{|l|}{ Serum 48 h } \\
\hline$\%$ Dose/g & 0.0022 & 0.0022 & 0.0023 & 0.0026 \\
\hline
\end{tabular}

$L R$

B
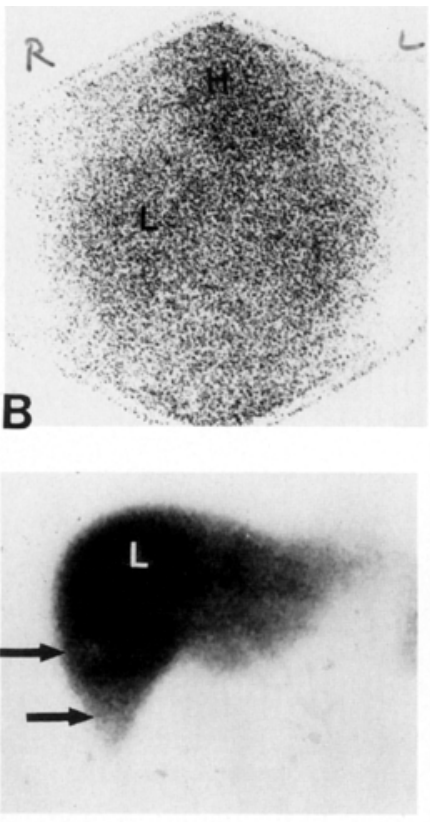

E

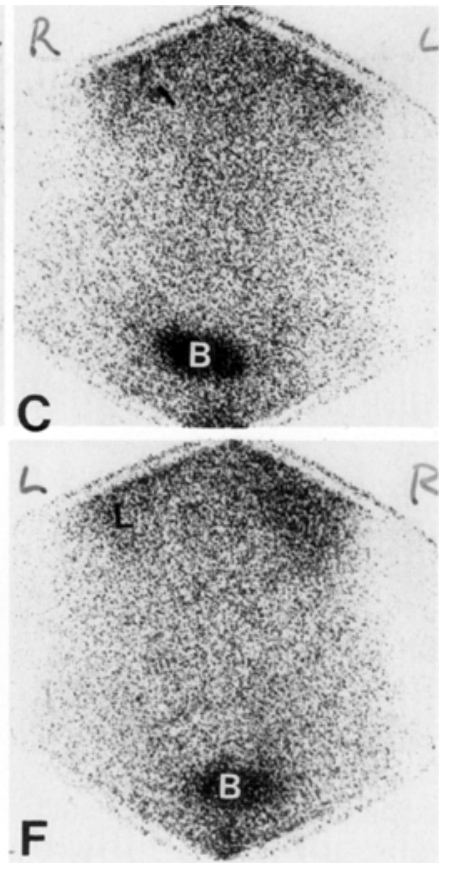

Fig. 2. Scintigraphic depiction of the distribution of ${ }^{131}$ I-PIPA in a human subject with carcinoid (A-C $24 \mathrm{~h}$ post-injection; D-F 48 h post-injection).

$\mathbf{A}$ and $\mathbf{D}$ anterior chest, $\mathbf{B}$ anterior chest/abdomen, $\mathbf{C}$ and $\mathbf{F}$ anterior abdomen/pelvis, $\mathbf{E}$ anterior abdomen of $99 \mathrm{mTc}$-sulphur colloid liver scan showing photopenic defects due to metastases (arrows). ( $H$ heart, $B$ bladder, $L$ liver) 
Table 4. Clinical features and scan results of patients studied with ${ }^{131} \mathrm{I}-$ and ${ }^{123} \mathrm{I}-\mathrm{MIBG}$

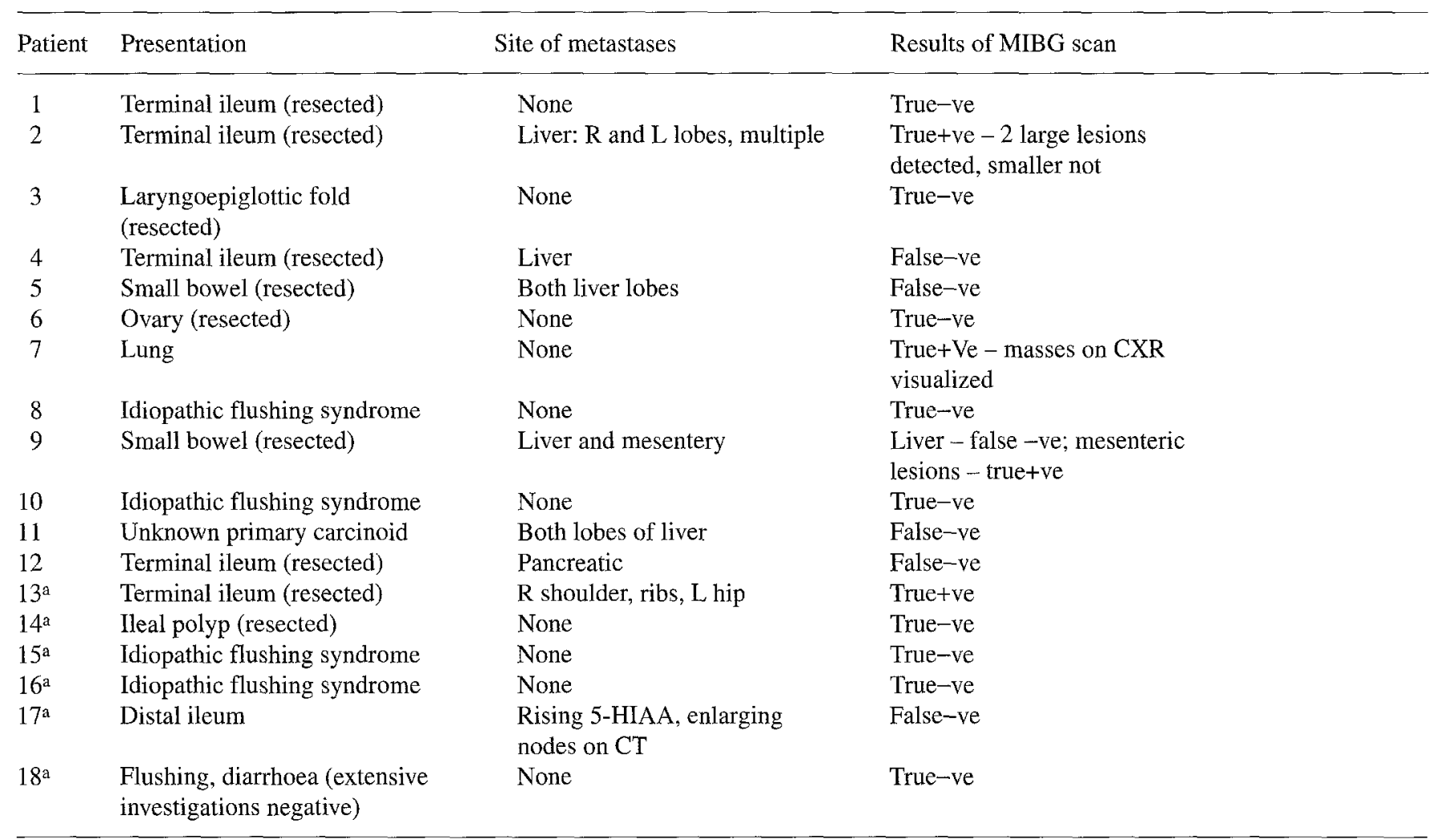

a Indicates studied with ${ }^{123}$ I-MIBG; all others with ${ }^{131}$ I-MIBG

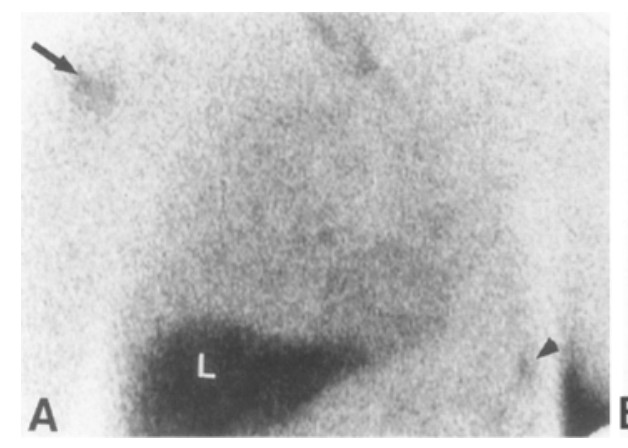

Fig. 3. Anterior planar images of the chest showing moderate uptake of ${ }^{123} \mathrm{MIBG}$ in a carcinoid deposit in the right shoulder (arrow) and anterior left rib (arrowhead) in patient 13 (A). The cor-

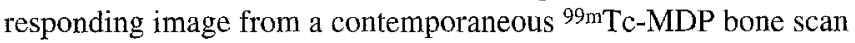

aged 1, 2 and 3 days later using a large field-of-view gamma camera equipped with a high-energy collimator and interfaced to a dedicated minicomputer. Multiple overlapping planar views of $20 \mathrm{~min}$ each were acquired from skull to pelvis. Thyroid uptake of free ${ }^{131}$ I-iodide was blocked by the administration of oral iodides for 24 $\mathrm{h}$ prior to and 1 week following injection with ${ }^{131} \mathrm{I}$ MIBG. With ${ }^{123}$ I-MIBG $10 \mathrm{mCi}$ (specific activity 10-40 $\mathrm{mCi} / \mathrm{mg}$ ) was administered intravenously and the patient imaged at 4 and $24 \mathrm{~h}$ post-injection, using a general-purpose collimator and gamma camera and the same views and acquisition times as for ${ }^{131} \mathrm{I}-\mathrm{MIBG}$. Thyroid uptake of free ${ }^{123}$ I as iodide was also blocked by administration of stable iodide solution.

\section{Results: ${ }^{131} I-$ and ${ }^{123} I-M I B G$ studies}

Among the 12 patients studied with ${ }^{131}$ I-MIBG, three of the seven patients with known primary or metastatic disease had positive ${ }^{131}$ I-MIBG scans, although in one of the three patients the ${ }^{131}$ I-MIBG scan demonstrated known mesenteric metastases but failed to localize in hepatic metastases seen on CT (see Table 4). Both patients 
Table 5. Clinical features and scan results of patients studied with ${ }^{111}$ In-pentetreotide

\begin{tabular}{llll}
\hline Patient & Primary findings & Metastatic disease & 111 In-pentetreotide results \\
\hline 1 & Unknown primary & $\begin{array}{l}\text { Extensive small bowel } \\
\text { mesentery and liver }\end{array}$ & $\begin{array}{l}\text { False-ve for liver lesions; true } \\
+ \text { ve for bowel } \\
\text { True-ve }\end{array}$ \\
2 & MEN IIa - recurrent medullary & None & \\
& Ca thyroid & None & True-ve \\
3 & Idiopathic flushing & Hepatic metastases & True+ve - 2 of larger lesions seen \\
\hline
\end{tabular}

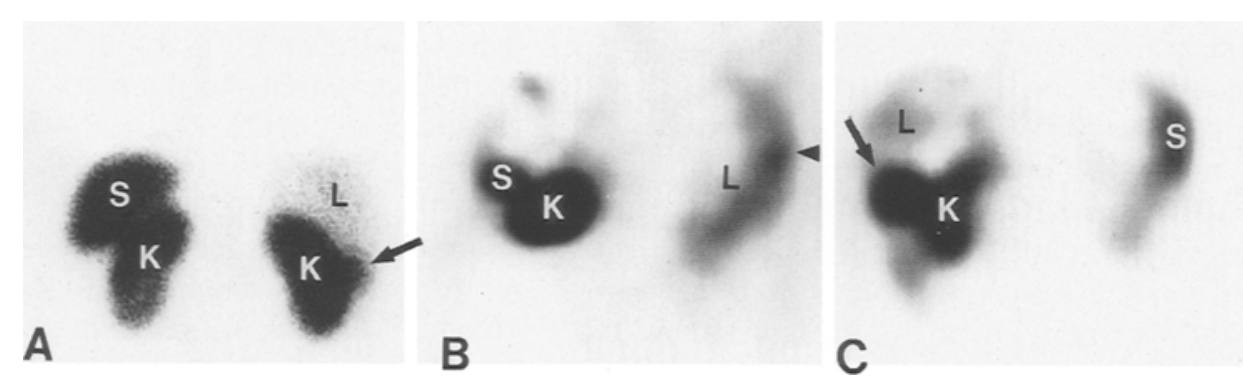

Fig. 4. A hepatic carcinoid metastasis (arrow) in patient 4 (Table 5) adjacent to the right kidney is identified by ${ }^{111}$ In-pentetreotide scanning on the planar posterior images of the upper abdomen (A). This lesion was more clearly seen (arrow) on representative transverse (not shown) and coronal (C) sections from single-pho-

with clinical evidence of locally recurrent disease had negative scans, as did the patient in whom the primary tumour was considered completely resected. The two patients with idiopathic flushing syndrome also had negative scans.

In the six patients studied with 123I-MIBG the results were as follows: In the patient with recurrent carcinoid, no abnormal uptake was evident in the involved paraaortic lymph nodes. Moderate uptake of tracer at best was seen in only some of the tumor deposits in the patient with distant metastatic disease (Fig. 3). The three patients diagnosed with idiopathic flushing syndrome after extensive investigation and the single patient with complete resection of an isolated primary tumour all yielded negative studies.

\section{Materials and methods: ${ }^{111}$ In-pentetreotide studies}

As ${ }^{111}$ In-penetreotide has only very recently been approved in the United States for the scintigraphic localization of carcinoid, our experience is limited. Nevertheless, we consider it important to compare and contrast results with this third approach to the scintigraphic depiction of carcinoid tumors with those with 131 I-PIPA and ${ }^{131} \mathrm{I}$ - and ${ }^{123} \mathrm{I}-\mathrm{MIBG}$. Because of the temporal differences in the availability of the radiopharmaceuticals, direct comparisons and not possible. Four patients with suspected or confirmed carcinoid tumour were studied: two with histological and biochemical proof of tumour presence, one after complete resection of a primary car- ton emission tomography of the region. A second lesion (arrowhead) in the anterior right lobe of liver is also apparent on a higher section on transverse tomography (B). ( $S$ spleen, $K$ kidney, $L$ liver)

cinoid, and a fourth with an idiopathic flushing syndrome (Table 5). None had received treatment with octreotide, or recent chemo- or radiotherapy. All were scanned with a modern dual-head gamma camera at 4 , 24 and $48 \mathrm{~h}$ after the intravenous injection of $6 \mathrm{mCi}$ of ${ }^{111}$ In-pentetreotide. Conjugate whole-body images (8 $\mathrm{cm} / \mathrm{min}$ ) were acquired at $4 \mathrm{~h}$, with overlapping planar views ( $15 \mathrm{~min}$ each) of the trunk at $24 \mathrm{~h}$ and single-photon emission tomography of the upper abdomen. The conjugate planar views were repeated at $48 \mathrm{~h}$. Laxatives were prescribed prior to imaging at 24 and $48 \mathrm{~h}$, and vigorous hydration encouraged.

\section{Results: ${ }^{111}$ In-pentetreotide studies}

Scintigraphic abnormalities at known sites of disease were evident in both patients with documented carcinoid tumour (Fig. 4). The studies were normal in the two patients in whom anatomical imaging and biochemical studies failed to disclose evidence of tumour.

\section{Discussion}

Historically, attempts to image carcinoid tumours with iodinated phenylalanine were followed by the use of ${ }^{131} \mathrm{I}-$ and ${ }^{123} \mathrm{I}-\mathrm{MIBG}$ and, later, ${ }^{111} \mathrm{In}$-pentetreotide for this purpose. It was considered important to document the false-negative results with ${ }^{131}$ I-PIPA in scintigraphy of carcinoid tumours. 
${ }^{131}$ I and ${ }^{123}$ I-MIBG, a radioiodinated arakylguanidine, is a physiological analogue of norepinephrine and of guanethidine [18]. It has been shown to enter the cells of the adrenal medulla by a specific energy-dependent uptake mechanism (uptake 1) in which it competes with norepinephrine, although the kinetics are not those of simple competitive inhibition [6]. Most of the MIBG concentrates in the intracellular granule fraction (see Fig. 1) [19]. The rationale for using MIBG in the imaging of carcinoid tumours is that these tumours also contain neurosecretory granules and are derived from the APUD cell line [19, 20].

The results of ${ }^{131}$ MIBG in the imaging of carcinoid tumours have been variable in the hands of numerous investigators. Fischer et al. first described the use of ${ }^{131} \mathrm{I}$ MIBG for scintigraphy of carcinoid in a patient with hepatic metastases, with areas of ${ }^{131}$ I-MIBG uptake in the liver corresponding to photopenic defects in hepatic tracer uptake seen on a technetium-99m phytate liver scan [21]. A recent review of the published experience with 131I-MIBG in carcinoid reported on an aggregate total of 275 patients from a variety of centres and protocols [6]. Of these, 194 patients were considered "true-positives", for an overall sensitivity of $70 \%$. In individual series $40 \%-100 \%$ of the patients with known carcinoid disease studied had positive ${ }^{131}$ MIBG scans. The aggregate results should be interpreted cautiously due to dissimilarities in detection critiera and other parameters between individual studies.

The experience at our institution with ${ }^{131}$ I-MIBG in the imaging of carcinoid tumours has not been as good as that of some other investigators. This may in part be related to methodology. Although the dose of $0.5 \mathrm{mCi}$ ${ }^{131}$ I-MIBG is small, this dose is capable of imaging approximately $85 \%$ of phaeochromocytmas and is the standard approved dose for ${ }^{131} \mathrm{I}-\mathrm{MIBG}$ in the USA. Feldman et al. appear to have improved the sensitivity of the agent by subtracting $99 \mathrm{~m} \mathrm{Tc}$-sulphur colloid liver scans from the ${ }^{131}$ I-MIBG images [22]. Both scans were performed within a period of a week. From the studies discussed above ${ }^{131}$ I-MIBG would appear to have high specificity but only moderate sensitivity in the imaging of carcinoid tumours. The experience with ${ }^{123} \mathrm{I}-\mathrm{MIBG}$ in carcinoid scintigraphy is much more limited, with one group describing positive scans (with varying intensity of tracer uptake within tumour) in six of seven patients with known metastatic disease $[23,24]$. Perhaps the relatively low specific activity of the radiopharmaceutical (especially the ${ }^{131}$ I-MIBG) played a role in this low sensitivity. Highly selected cases of the most MIBG-avid metastatic carcinoids may be candidates for experimental treatment with large doses of ${ }^{131}$ I-MIBG.

For somatostatin receptor scintigraphy initial studies utilized 123I- labelled somatostatin analogues, but the greatest experience to date is with ${ }^{111} \mathrm{In}$-penetetreotide. Many other cyclic and linear peptide analogues of somatostain have been synthesized, including $99 \mathrm{mTc}$ labelled compounds $[25,26]$. Overall sensitivity of in vivo carcinoid imaging with ${ }^{111}$ In-pentetreotide was reported as $86 \%$ in a recent review of published studies encompassing a total of 451 patients [6]. Similar sensitivities have been reported with CT and ${ }^{111}$ In-pentetreotide scintigraphy in determining the presence or absence of carcinoid tumour in patients [27]. However, the subgroups detected by the two modalities are not concordant, with scintigraphy tending to detect more lesions per patient, although histological confirmation of all the scintigraphic abnormalities as tumour was not always forthcoming. Sensitivity for detection of hepatic metastases is much greater with CT and ultrasonography than with ${ }^{111} \mathrm{In}$ penetetreotide, which may be attributed to variable uptake of tracer within hepatic metastases and the marked activity within normal hepatic parenchyma [27].

Although early studies classified tissues as being "positive" or "negative" for the presence of SSTRs, molecular biological techniques have illuminated a more complex scenario. Currently five distinct human SSTRs (designated SSTR 1-5) have been identified and sequenced (see Fig. 1). These range between 363 and 418 amino acid residues in size, exhibit considerable sequence identity and are encoded for by genes on different chromosomes [28, 29]. SSTR 1-4 are expressed widely, with relative receptor density and proportion varying between and within individual tissues [30]. SSTR 5 appears predominantly within brain. The various receptor subclasses exhibit differing affinities for the endogenous somatostatins and their synthetic analogues. Pentetreotide shows high affinity for SSTR 2, less for SSTRs 3 and 4, and virtually none for SSTRs 1 and 5 $[29,31]$. The limited SSTR subtyping performed on a small number of carcinoids may explain some of the false-negative studies. Probes for SSTRs 1-3 revealed that tumour expression of SSTR-3 was common (>50\%) while that of SSTRs 1 and 2 was less frequent [8]. Virtually all combinations of receptor expression were observed, including their total absence. Some of the falsenegative scintigraphic results with radiolabelled pentetreotide may therefore be explained by tumours expressing only receptors which do not bind pentetreotide, the low densities of high-affinity receptors (i.e. SSTR 2 or 3) or no receptors at all.

Unlike with MIBG and the radiolabelled somatostatin analogues, attempts to image carcinoid tumours with 131 I-PIPA were completely unsuccessful despite the excellent target-to-background ratio in a relevant animal model. While the reason for this difference is not clear, it may be related to the underlying physiology of the postulated mechanisms of tissue localization of the three agents (Fig. 1). MIBG, as previously discussed, is actively transported across the cytoplasmic membrane into the enterochromaffin tumours cells and subsequently stored within intracellular granules. ${ }^{111}$ In pentetreotide binds to the cell surface somatostatin receptors which are expressed with considerable frequency and density by this tumour type. It has been suggested that a proportion of the occupied somatostatin receptor complexes 
may subsequently be internalized, in a fashion analogous to a variety of other peptide hormones [6,32]. PIPA acts by binding to and inhibiting tryptophan hydroxylase, the rate-limiting enzyme in serotonin synthesis. The ${ }^{131} \mathrm{I}-$ PIPA would first have to be transported into the intracellular compartment before gaining access to tryptophan hydroxylase. Rapid enzyme turnover and the high affinity but low capacity of the enzyme for substrate and the intracellular location may in part explain the failure of this agent to depict human carcinoid tumours. Enzymes characteristically exert powerful metabolic effects even when present in minute quantities. The small activity of 131I-PIPA under these circumstances would provide insufficient photon flux for imaging. The use of 123I-PIPA in larger doses might be contemplated but was not pursued in light of the completely negative ${ }^{131}$ I-PIPA studies (most phaeochromocytomas and on average $70 \%$ of carcinoids are satisfactorily imaged with a similar dose of ${ }^{131} \mathrm{I}-\mathrm{MIBG}$ ). The limited binding capacity of the enzyme contrasts with the potentially large storage capacity of the hormonal storage vesicles, or somatostatin receptor density. Despite the failure in the case of human carcinoid, the general concept of using labelled enzyme inhibitors nevertheless remains attractive and potentially feasible, as demonstrated by the localization of ${ }^{131}$ IPIPA in the mouse mastocytoma model and the successful development of radiolabelled adrenocortical synthesis inhibitors [33, 34].

\section{Conclusion}

One aim of this study was to evaluate the use of radiolabelled compounds targeted at the enzymes of the serotonin synthetic pathway of carcinoid tumours as possible imaging agents for these lesions. A competitive inhibitor of tryptophan hydroxylase - 131 I-PIPA - was synthesized and administered to four patients with known metastatic carcinoid tumours. In vivo imaging was unsuccessful despite good tracer targeting in an appropriate animal model. It is conceivable that the concentration of enzyme relative to tumour bulk was too small to permit imaging.

Tracing the reuptake and storage of biogenic amines with ${ }^{131}$ I (and probably ${ }^{123}$ I) MIBG provides a useful but imperfect tool for detection of carcinoid tumours with an average sensitivity of $70 \%$, and good specificity. This is less sensitive than ${ }^{111}$ In-pentreotide, which must now be considered the radiopharmaceutical of choice. Nevertheless, a selected minority of MIBG-avid carcinoids may be treatable with large doses of ${ }^{131}$ I-MIBG.

The dense expression of somatostatin receptors by most carcinoids has made ${ }^{111}$ In-pentetreotide scintigraphy the most sensitive current scintigraphic diagnostic technique. The scintigraphic demonstration of somatostatin receptors may predict the therapeutic response to non-radioactive somatostatin analogue therapy. However, even this agent is limited by factors including multiple sites of prominent upper abdominal physiological background activity, relative lack of specificity, and the existence of occasional tumours without appropriate receptors.

\section{References}

1. Vinik AI, McLeod M, Fig LM, Shapiro B, Lloyd R, Cho K. Clinical features, diagnosis, and localization of carcinoid tumors and their management. Gastroenterol Clin North Am 1989; 18: 865-896.

2. Hosoda S. Carcinoid tumours - review of literature with special references to sites of origin and humoral substances produced. Acta Pathol Jpn 1972; 22: 533-540.

3. Sjoerdsma A, Lovenberg W, Engelman K, Carpenter WT, Wyatt RJ, Gessa GL. Serotonin now: Clinical implications of inhibiting its synthesis with para-chlorophenylalanine. Ann Int Med 1970; 73: 607-629.

4. Engelman K, Lovenberg W, Sjoerdsma A. Inhibition of serotonin synthesis by $p$-chlorophenylalanine in patients with carcinoid syndrome. N Engl Med 1967; 277: 1103-1108.

5. Costella C. Experiments with advanced carcinoids. Am J Surg 1963; 106: 537

6. Hoefnagel CA. Metaiodobenzylguanidine and somatostatin in oncology: role in the management of neural crest tumors. Eur J Nucl Med 1994; 21: 561-581.

7. Thulin L, Samnegård $\mathrm{H}$, Tydén $\mathrm{G}$, Long DH, Efendic S. Efficacy of somatostatin in a patient with carcinoid syndrome. Lancet 1978; II: 43.

8. Reubi JC, Kvols LK, Waser B, et al. Detection of somatostatin receptors in surgical and percutaneous needle biopsy of carcinoids and islet cell carcinomas. Cancer Res 1990; 50: 5969-5977.

9. Reubi JC, Krenning E, Lamberts SWJ, Kvols L. In vitro detection of somatostatin receptors in human tumors. Metabolism 1992: 41 [Suppl2]; 104-110.

10. Mangner TJ, Brown LE, Wieland DM, Beierwaltes WH. Potential radio-pharmaceuticals for diagnosis and treatment of carcinoid tumor [abstract]. J Label Compds Radiopharm 1981; 18: 45.

11. Lambrecht RM, Atkins H, Elias H, Fowler JS, Lin SS, Wolf AP. A novel I-123 labeling agent. XIII: Synthesis and loading dose effects of I-123 iodophenylalanine and I-123 5- and 6iodotryptophan. J Nucl Med 1974; 15: 863-867.

12. Furth J, Hagen P, Hirsch EI. Transplantable mastocytoma in the mouse containing histamine, heparin, 5-hydroxytryptamine. Proc Soc Exp Biol Med 1957; 95: 824.

13. Ono S, Zompetti L, Hagn P, Furth J. Relation of mastocytoma to mast cell leukemia and of heparin, histamine and serotonin to mast cells. Blood 1995; 14: 770 .

14. Hosoda S. Further studies on tryptophan hydroxylase from neoplastic murine mast cells. Biochim Biophys Acta 1975; 397: 58-68.

15. Hosoda S, Nakamura W, Takatsuki K. Properties of tryptophan hydroxylase from human carcinoid tumor. Biochim Biophys Acta 1977; 482: 27-34.

16. Snyder WS, Ford MR, Warner GG, Watson SB. "S" absorbed dose per unit cumulated activity for selected radionuclides and organs. In: NM/MIRD Pamphlet 11. New York: Society of Nuclear Med, 1975.

17. Von Moll L, McEwan AJ, Shapiro B, et al. Iodine-131 MIBG scintigraphy of neuroendocrine tumors other than pheochromocytoma and neuroblastoma. $J$ Nucl Med 1987; 28: 979-988. 
18. Nakajo M, Shapiro B, Copp J, Kalff V, Gross MD, Sisson JC, Beierwaltes WH. The normal and abnormal distribution of the adrenomedullary imaging agent $m$-[1-131]-iodobenzylguanidine (1-131 MIBG) in man: evaluation by scintigraphy. $J$ Nucl Med 1983; 24: 672-682.

19. Tobes MC, Jaques S, Wieland DM, Sisson J. Effect of uptakeone inhibitors on re-uptake of norepinephrine and metaiodobenzylguanidine. J Nucl Med 1985; 26: 897-907.

20. Solcia E, Capella C, Fiocca R, Cornaggia M, Bosi F. The gastroenteropancreatic endocrine system and related tumors. Gastroenterol Clin North Am 1989; 18: 671-693.

21. Fischer M, Kamanabroo D, Sonderkamp H, Proske T. Scintigraphic imaging of carcinoid tumours with I-131 metaiodobenzylguanidine [letter]. Lancet 1984; II: 165.

22. Feldman JM, Blinder RA, Lucas KJ, Coleman RE. Iodine-131 metaiodobenzylguanidine scintigraphy of carcinoid tumors. $J$ Nucl Med 1986: 27; 1691-1696.

23. Bomanji J, Levison DA, Zuzarte J, Britton KE. Imaging of carcinoid tumours with iodine-123 metaiodobenzylguanidine. I Nucl Med 1987: 28; 1907-1910.

24. Bomanji J, Ur E, Mather S, et al. A scintigraphic comparison of iodine-123-metaiodobenzylguanidine and an iodine-labeled somatostatin analog (Tyr-3-octreotide) in metastatic carcinoid tumors. J Nucl Med 1992; 33: 1121-1124.

25. Srkalovic G, Cai R, Schally AV. Evaluation of receptors for somatostatin in various tumors using different analogs. $J$ Clin Endocrinol Metab 1990; 70: 661-669.

26. Amartey JK. Technetium-99m labeled somatostatin and analogs: synthesis, characterization and in vitro evaluation. $\mathrm{Nucl}$ Med Biol 1993; 20: 539-543.
27. Westlin JE, Janson ET, Arnberg H, Ahlström H, Öberg K, Nilsson S. Somatostatin receptor scintigraphy of carcinoid tumors using the [111In-DTPA-D-Phe $\left.{ }^{1}\right]$-octreotide. Acta Oncol 1993; 32: 783-786.

28. Yamada Y, Stoffel M, Espinosa R, et al. Human somatostatin receptor genes: localization to human chromosomes 14,17 , and 22 and identification of simple tandem repeat polymorphisms. Genomics 1993; 15: 449-452.

29. Panetta R, Greenwood MT, Warszynska A, et al. Molecular cloning, functional characterisation, and chromosomal localization of a human somatostatin receptor (somatostatin receptor type 5) with preferential affinity for somatostatin-28. $\mathrm{Mol}$ Pharmacol 1994; 45: 417-427.

30. Kaupmann K, Bruns C, Hoyer D, Seuwen K, Lübbert H. Distribution and second messenger cupling of four somatostatin receptor subtypes expressed in brain. FEBS Lett 1993; 1: 53-59.

31. Yamada Y, Kagimoto S, Kubota A, et al. Cloning, functional expression and pharmacological characterization of a fourth (hSSTR4) and a fifth (hSSTR5) human somatostatin receptor subtype. Biochem Biophys Res Commun 1993; 195: 844-852.

32. Catt KJ, Harwood JP, Aquilera G, Dufau ML. Hormonal regulation of peptide receptors and target cell responses. Nature 1979; 280: 109-116.

33. Gross MD, Valk TW, Swanson DP, Thrall JH, Grekin RJ. Beierwaltes WH. The role of pharmacological manipulation in adrenal cortical scintigraphy. Semin Nucl Med 1981; 11: 128-148.

34. Beierwaltes WH, Wieland DM, Mosley ST, et al. Imaging the arenal glands with radiolabeled inhibitors of enzymes: concise communication. J Nucl Med 1978; 19: 200-203. 